\title{
Integrated interdisciplinary care for patients with chronic obstructive pulmonary disease reduces emergency department visits and admissions: A quality assurance study
}

\author{
Esther Dajczman N MScA ${ }^{1,2,3}$, Chantal Robitaille PhD11, Pierre Ernst MD¹, Andrew Michael Hirsch MD ${ }^{1}$, \\ Norman Wolkove MD ${ }^{1,2}$, David Small MD¹, Judy Bianco N MScA ${ }^{3}$, Hartley Stern MD ${ }^{3}$, Mark Palayew MD ${ }^{1}$
}

\begin{abstract}
E Dajczman, C Robitaille, P Ernst, et al. Integrated interdisciplinary care for patients with chronic obstructive pulmonary disease reduces emergency department visits and admissions: A quality assurance study. Can Respir J 2013;20(5):351-356.
\end{abstract}

BACKGROUND: Dedicated programs for the management of chronic obstructive pulmonary disease (COPD) can reduce hospitalizations and improve quality of life.

OBJECTIVE: To investigate whether health care utilization could be reduced by a newly developed integrated, interdisciplinary initiative that included a COPD nurse navigator who educates patients and families, transitions patients through various points of care and integrates services. METHODS: The present quality assurance, pre-post study included patients followed by a COPD nurse navigator from January 25, 2010 to November 5, 2011. Information regarding emergency department visits and hospitalizations, including lengths of stay, were obtained from hospital databases. Diagnoses were classified as respiratory or nonrespiratory, and used primary and secondary hospitalization diagnoses to identify acute exacerbations of COPD (AECOPD). Paired sign tests were performed. RESULTS: The sample consisted of 202 patients. Following nurse navigator intervention, significantly more patients experienced a decrease in the number of respiratory-cause emergency department visits $(\mathrm{P}<0.05)$, number of respiratory hospitalizations $(\mathrm{P}<0.001)$, total hospital days for respiratory admissions $(\mathrm{P}<0.001)$, number of hospitalizations with AECOPD $(\mathrm{P}<0.001)$ and total hospital days for admissions with AECOPD $(\mathrm{P}<0.001)$. Financial modelling estimated annual savings in excess of $\$ 260,000$. CONCLUSION: The present quality assurance study indicated that the implementation of an integrated interdisciplinary program for the care of patients with COPD can improve patient outcomes despite the tendency of COPD to worsen over time.

Key Words: Acute exacerbation of COPD; Chronic obstructive pulmonary disease; Health care utilization; Interdisciplinary team, Partnered management

Chronic obstructive pulmonary disease (COPD) is the fourth leading cause of mortality in Canada $(1,2)$ and is associated with decreased quality of life (QoL) (3-6). This chronic illness is characterized by frequent exacerbations and comorbidities that can result in emergency department (ED) visits and hospitalizations (7-9). Acute exacerbations of COPD (AECOPD) can lead to further loss of lung function $(10,11)$, increased morbidity and mortality $(8,12,13)$, and are an important predictor of future events $(8,14)$. Exacerbations are also associated with decreased QoL (15-17) and generate significant costs to the health care system $(12,18-20)$.

COPD programs have focused on helping patients and families take charge of their illness $(21,22)$. Transitional care programs for patients with chronic illnesses promote the support of patients across episodes of care (23). Both strategies have been shown to improve

\section{Les soins interdisciplinaires intégrés des patients ayant une maladie pulmonaire obstructive chronique réduisent les visites à l'urgence et les hospitalisations : une étude d'assurance-qualité}

HISTORIQUE : Des programmes voués à la prise en charge de la maladie
pulmonaire obstructive chronique (MPOC) peuvent limiter les hospitalisa-
tions et améliorer la qualité de vie.
OBJECTIF : Examiner s'il est possible de réduire l'utilisation des soins de
santé grâce à une nouvelle initiative interdisciplinaire intégrée qui incluait
une infirmière pivot spécialisée en MPOC qui éduquait les patients et les
familles, assurait la transition des patients entre les divers points de services et
intégrait les services. MÉTHODOLOGIE : La présente étude avant-après d'assurance-qualité se composait de patients suivis par une infirmière pivot spécialisée en MPOC entre le 25 janvier 2010 et le 5 novembre 2011. Les chercheurs ont tiré des bases de données hospitalières l'information relative aux consultations à l'urgence et aux hospitalisations, y compris la durée de séjour. Ils ont classé les diagnostics entre une nature respiratoire ou non respiratoire et ont utilisé les diagnostics d'hospitalisation primaire et secondaire pour établir les exacerbations aiguës de MPOC (EA-MPOC). Ils ont effectué des tests de signes appariés.

RESULTATS : L'échantillon était formé de 202 patients. Après l'intervention de l'infirmière pivot, un nombre nettement plus élevé de patients présentaient une diminution du nombre de consultations à l'urgence pour des causes respiratoires $(\mathrm{P}<0,05)$, du nombre d'hospitalisations pour des causes respiratoires $(\mathrm{P}<0,001)$, de journées totales d'hospitalisation pour des causes respiratoires $(\mathrm{P}<0,001)$, du nombre d'hospitalisations en raison d'EA-MPOC $(\mathrm{P}<0,001)$ et de journées totales d'hospitalisations en raison d'une EA-MPOC $(\mathrm{P}<0,001)$. D'après la modélisation financière, on estimait des économies annuelles de plus de 260000 \$.

CONCLUSION : La présente étude d'assurance-qualité révèle que la mise en œuvre d'un programme interdisciplinaire intégré pour soigner les patients ayant une MPOC peut améliorer les issues des patients malgré la tendance à la détérioration de la MPOC au fil du temps.

outcomes such as QoL, number of admissions to hospital, total hospital days and costs $(21,22,24,25)$. To optimize COPD patient services across lines of care, an integrated interdisciplinary program was developed and led by an advanced practice nurse (APN [COPD nurse navigator]). In the present quality assurance study, we hypothesized that this program would lead to a reduction in health care utilization.

Study design

\section{METHODS}

A quality assurance, pre-post intervention study examining the impact of an integrated interdisciplinary program for COPD on health care utilization was performed. The study was approved by the Jewish General Hospital (JGH, Montreal, Quebec) Research Ethics Committee (Ethics \# CR12-13).

\footnotetext{
${ }^{1}$ Airways Centre, Division of Pulmonary Diseases, Jewish General Hospital, McGill University, Montreal; ${ }^{2}$ Mount Sinai Hospital Center, Cote-Sait-Luc; ${ }^{3}$ Jewish General Hospital, McGill University, Montreal, Quebec

Correspondence and reprints: Dr Chantal Robitaille, Division of Pulmonary Diseases, Department of Internal Medicine, Jewish General Hospital, 3755 Chemin de la Côte-Ste-Catherine, Pavilion G, Room 203, Montreal, Quebec H3T 1E2. Telephone 514-340-8222 ext 3636,

fax 514-340-7555, e-mail chantal.robitaille@jgh.mcgill.ca
} 


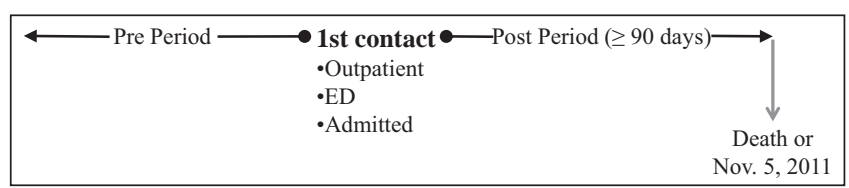

Figure 1) Pre-and postobservation periods. ED Emergency department

\section{Participants and setting}

The present study included patients followed by the COPD nurse navigator from January 25, 2010 (start date of the program) to November 5, 2011 (close of the study) at the JGH. Patients with a physician's diagnosis of COPD were referred to the program at the discretion of a pulmonary physician, or ED or ward personnel. Reasons for referral included nurse navigator support, patient education and assessment for services. Patients already on long-term oxygen therapy were followed under another program. Individuals with a follow-up observation period $<90$ days were excluded from the analyses.

\section{Description of the program}

Within this integrated interdisciplinary program, an APN was introduced as the nurse navigator for the care of patients with COPD. She is a Master's prepared clinical nurse specialist with extensive experience in pulmonary diseases working in a tertiary care hospital. The COPD nurse navigator sees patients with or without the physician depending on patient needs. She provides education to patients and their caregivers based on the 'Living Well with COPD' program (Boehringer Ingleheim) (21) and helps patients cope with their illness through partnered disease management. She is available by telephone, pager and e-mail to answer questions, assess the need for an action plan or arrange for further assessment. Central to the interdisciplinary program is the nurse-physician partnership based on collaboration and communication. This relationship benefits patients by improving their access and interactions with the health care team. The nurse navigator facilitates timely transfers to other institutions, particularly an affiliated centre specializing in pulmonary care and rehabilitation (Mount Sinai Hospital Centre, Cote-Saint-Luc, Quebec), where she continues to follow patients. She is available throughout transitions to address patients' complex needs and promote continuity of care. She functions as a single 'point person' present across lines of care providing consistent access to the same health care provider and fostering communication within the interdisciplinary team. The interdisciplinary team also includes a smoking-cessation counselor who is available during clinics. All members of the team promote healthy lifestyle changes.

\section{Procedures}

Visits and contacts with the nurse navigator, ED visits, hospital admissions and lengths of stay (LOS) were obtained from hospital databases. Postobservation duration was calculated for each patient based on his/ her first contact with the COPD nurse navigator to either the date of death or November 5, 2011. The maximum postobservation period was 22 months. The preobservation period for each patient was made equal in duration to the postobservation period (Figure 1).

ED diagnoses were classified as respiratory (eg, COPD, bronchitis, pneumonia, influenza, dyspnea, cough) or other. Discharge diagnoses for hospital admissions according to the International Classification of Diseases, 10th Revision (ICD-10) were obtained. Primary discharge diagnoses were coded as respiratory or other. Admissions were considered to involve an AECOPD if the primary diagnosis was ICD-10 code J40-44 or if secondary diagnoses included J44.0 or J44.1, regardless of primary diagnosis.

\section{Statistical analysis}

The primary outcomes were number of all-cause ED visits and admissions, as well as all-cause total hospital days. Secondary outcomes were the number of respiratory-cause ED visits and admissions as well as respiratory-cause total hospital days. To take into account the paired nature of the data and the non-normal distribution of the pre-post differences, two-sided paired sign tests were conducted. Per cent differences are provided for illustration and were calculated by dividing the absolute difference between the pre- and postobservation period values by the preobservation period values. To evaluate the potential bias caused by including the initial visit with the nurse navigator occurring during an ED visit or hospital admission, the analyses were repeated removing the index visit from the preobservation period. All analyses were performed using SPSS version 19 (IBM Corporation, USA).

For illustrative purposes, an ad hoc analysis was conducted to estimate the economic impact of the program. This was performed using the assessment of cost for an AECOPD to the Canadian health care system reported by Mittmann et al (20). To calculate ED visit costs in the present study, Mittman et al's total emergency resource cost (intent-to-treat analysis) was used. For admission costs, Mittman et al's total emergency resource costs of severe exacerbations were added to total hospital resource costs because most patients hospitalized first came through the ED. Pre-post cost differences were adjusted for inflation using Canadian Core Consumer Price Index May 2006 to May 2012 (26). Program costs included the salary and benefits for the APN, pager, telephone line, cellular telephone, laptop computer and expenses for travel between institutions. Depending on the level of experience of the APN, these costs may vary between $\$ 75,000$ to $\$ 96,500$ per year. Because this was not a formal cost analysis, other potential added costs to the system (eg, changes in medication, increased outpatient visits) were not taken into account.

\section{Participants}

\section{RESULTS}

The COPD nurse navigator followed 229 patients over the study period. Twenty-seven patients were excluded because they had a follow-up period $<90$ days. The final study sample, therefore, included 202 patients. Mean age at first contact was 71.8 years and women represented $50 \%$ of the population. The majority of patients were initially seen in the outpatient clinic. The nurse navigator had an average of four contacts per patient over the study period (Table 1).

\section{ED visits}

The number of all-cause ED visits increased slightly between the preand postobservation periods (139 versus 145 [4\% increase]); however, the number of respiratory-cause ED visits decreased (61 versus 38 [38\% decrease]). The paired sign test compared the number of patients with more, fewer and the same number of visits pre- and postintervention. Analyses indicated that significantly more patients experienced a decrease in the number of respiratory-cause ED visits following nurse navigator intervention $(\mathrm{P}<0.05)$ (Figure 2$)$.

\section{Admissions}

Admissions were categorized according to primary discharge diagnosis. There was a decrease in the number of hospital admissions, both allcause (164 versus 108 [34\% decrease]) and respiratory cause (97 versus 39 [60\% decrease]), from the pre- to postobservation period. Significantly more patients had a decrease in the number of all-cause $(\mathrm{P}<0.001)$ and respiratory-cause admissions $(\mathrm{P}<0.001)$ after their entry into the program (Figure 3 ). Reductions in total hospital days for all-cause (1944 versus 1235 [37\% decrease]) and respiratory-cause (1114 versus $321 \quad$ [71\% decrease]) admissions were observed. Significantly more patients experienced a decrease in total hospital days for all-cause $(\mathrm{P}<0.001)$ and respiratory-cause $(\mathrm{P}<0.001)$ admissions from the pre- to postobservation periods (Figure 3 ).

Admissions were also categorized according to the presence or absence of an AECOPD. The number of admissions involving an AECOPD decreased from the pre- to the postobservation periods (108 versus 44 [59\% decrease]) while admissions without an AECOPD increased (56 versus 64 [14\% increase]). Significantly more patients had fewer admissions involving an AECOPD from the pre- to postobservation periods $(\mathrm{P}<0.001)$ (Figure 4$)$. A pre-post reduction in total hospital days of admissions involving AECOPD was observed 
TABLE 1

Patient characteristics $(n=202)$

\begin{tabular}{|c|c|}
\hline Characteristic & \\
\hline Age, years, mean $\pm S D$ & $71.8 \pm 9.7$ \\
\hline Male sex & $101(50)$ \\
\hline \multicolumn{2}{|l|}{ First contact with nurse navigator } \\
\hline Outpatient & $145(71.8)$ \\
\hline Inpatient & $52(25.7)$ \\
\hline ED & $5(2.5)$ \\
\hline \multicolumn{2}{|l|}{ Smoking habits } \\
\hline Current smokers & $64(31.7)$ \\
\hline Pack-years, mean $\pm S D$ & $41.6 \pm 26.8$ \\
\hline Ex-smokers & $125(61.9)$ \\
\hline Never-smokers & $11(5.4)$ \\
\hline $\mathrm{FEV}_{1}, \mathrm{~L}$, mean $\pm \mathrm{SD}$ & $1.18 \pm 0.48$ \\
\hline $\mathrm{FEV}_{1} \%$ predicted, mean $\pm \mathrm{SD}$ & $53.1 \pm 20.3$ \\
\hline $\mathrm{FEV}_{1} / \mathrm{FVC}$, mean $\pm \mathrm{SD}$ & $0.52 \pm 0.13$ \\
\hline \multicolumn{2}{|l|}{ Number of preperiod ED visits } \\
\hline 0 visit & $137(67.8)$ \\
\hline 1 visit & $40(19.8)$ \\
\hline$\geq 2$ & $25(12.4)$ \\
\hline \multicolumn{2}{|l|}{ Number of preperiod admissions } \\
\hline 0 & $106(52.5)$ \\
\hline 1 & $60(29.7)$ \\
\hline$\geq 2$ & $36(17.8)$ \\
\hline \multicolumn{2}{|c|}{ Number of contacts with nurse navigator } \\
\hline 1 & $61(30.2)$ \\
\hline 2 to 4 & 77 (38.1) \\
\hline$\geq 5$ & $64(31.7)$ \\
\hline Mean \pm SD & $4.0 \pm 3.6$ \\
\hline Median (range) & $3.0(1-25)$ \\
\hline Follow-up, days, mean \pm SD & $394 \pm 156$ \\
\hline Median (range) & $390(94-649)$ \\
\hline
\end{tabular}

Data presented as $n$ (\%) unless otherwise indicated. ED Emergency department; FEV ${ }_{1}$ Forced expiratory volume in $1 \mathrm{~s}$; FVC Forced vital capacity

(1495 versus 414 [79\% decrease]). Meanwhile, total hospital days not involving an AECOPD increased (449 versus 821 [83\% increase]). Paired sign tests indicated that significantly more patients had decreased total hospital days involving an AECOPD from the pre- to postobservation periods $(\mathrm{P}<0.001)$ (Figure 4).

Sensitivity analyses

In the sensitivity analyses, the initial visit was excluded from the prepost comparison. No significant differences were observed in the number of patients who increased or decreased their number of allcause and respiratory-cause ED visits. For respiratory-cause admissions, significantly more patients had a decrease in number of admissions and total hospital days during the postobservation period $(\mathrm{P}<0.05)$.

\section{Potential economic impact}

The estimated cost savings in relation to ED and hospital admissions for respiratory cause totalled $\$ 630,600$ during the study period. Based on the upper end of the estimated program cost, this represented an annual cost saving of $\$ 263,840$ (Table 2).

\section{DISCUSSION}

We found that the introduction of an interdisciplinary integrated approach to COPD care led to a decrease in health care utilization. Significantly more patients experienced a decrease in the number of respiratory-cause ED visits, all-cause and respiratory-cause admissions as well as reduced total LOS.

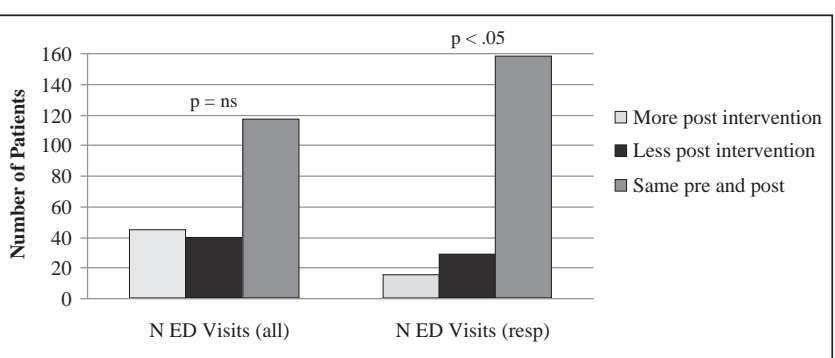

Figure 2) Emergency department (ED) visits postintervention compared with preintervention. ns Not statistically significant; resp Respiratory cause

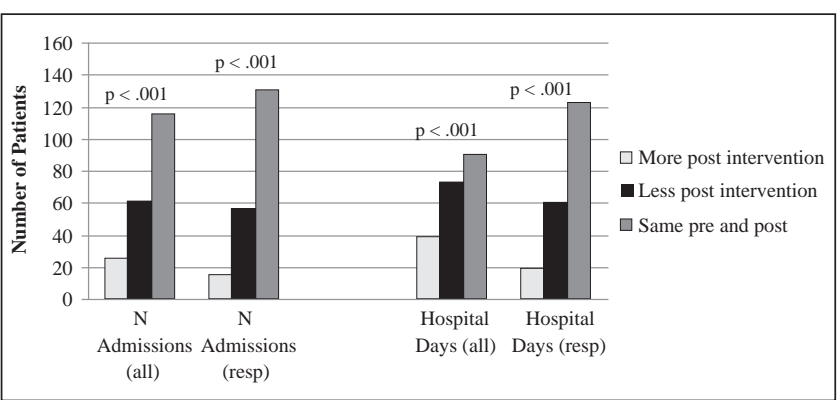

Figure 3) Hospital admissions postintervention compared with preintervention. resp Respiratory cause

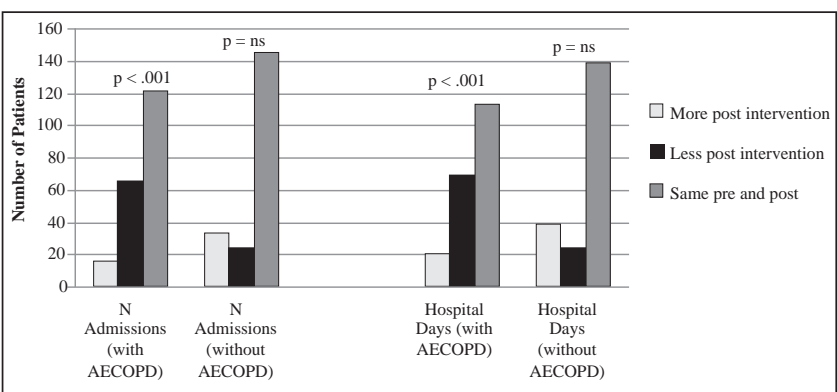

Figure 4) Admissions with and without acute exacerbations of chronic obstructive pulmonary disease (AECOPD). ns Not statistically significant

Many strategies have been proposed to help improve outcomes in COPD (21,22,27-31). A pivotal study by Bourbeau et al (21), on which our program is partially based, showed a significant reduction in hospital admissions. Patients were followed by a case manager using a self-management education program, integrated supervision and continuous support. The economic impact of the intervention did not show cost savings due to low caseloads (14 patients per case manager); however, cost savings were predicted with caseloads of 50 patients per case manager (24). In our quality assurance study, the nurse navigator followed $>200$ COPD patients over a 21 -month period. The number and type of contacts (eg, out-/inpatient visits, telephone, e-mail) varied, as might be expected with the implementation of a program in a clinical setting. Our estimated savings due to decreased admissions and ED visits was $>\$ 260,000$ per year.

Rea et al (22) randomly assigned general practices to an intensive chronic disease management program versus conventional care for patients with moderate to severe COPD. The intensive program included pulmonary rehabilitation, patient-specific care plans and enhanced information sharing among health care providers. The mean bed days/patient per year for respiratory causes decreased in the intensive management group; however, only 83 patients received the intervention within 20 practices. Our program is integrated within the respiratory disease division of an academic hospital, involved a 
TABLE 2

Cost comparison between pre- and postemergency department (ED) visits and hospital admissions for respiratory causes

\begin{tabular}{|c|c|c|c|c|c|}
\hline & $\begin{array}{c}\text { ED visit for } \\
\text { respiratory cause, } n\end{array}$ & $\begin{array}{c}\text { Costs } \\
\text { \$515/ED visit* }\end{array}$ & $\begin{array}{c}\text { Admission for } \\
\text { respiratory cause, } n\end{array}$ & $\begin{array}{c}\text { Costs } \$ 9,443 / \\
\text { admission* }\end{array}$ & Total costs, $\$$ \\
\hline Pre & 61 & $\$ 31,415$ & 97 & $\$ 915,971$ & 947,386 \\
\hline Post & 38 & $\$ 19,570$ & 39 & $\$ 368,277$ & 387,847 \\
\hline Cost reductions adjusted for inflation & & $\$ 13,349$ & & $\$ 617,251$ & 630,600 \\
\hline Adjusted cost reduction per annum & & $\$ 7,628$ & & $\$ 352,715$ & 360,343 \\
\hline
\end{tabular}

*As estimated by Mittman et al (20). Bolded values represent savings per year before and after accounting for costs

greater number of patients, and resulted in a decrease in the number of all-cause and respiratory-cause total hospital days.

Hermiz et al (29) evaluated the usefulness of limited communitybased care for patients with COPD following discharge from hospital. This included home visits by a community nurse one and four weeks postdischarge, and preventive general practitioner care. Although patients' knowledge and some aspects of QoL improved following the intervention, presentation and readmission to hospital within three months following discharge was unchanged. Our intervention focuses on integrated chronic care management following the patient across episodes of care. Our results suggest that this type of intervention can improve outcomes over a longer period of time.

A trial based in Veterans Affairs medical centres (28) randomly assigned 743 patients with severe COPD to usual care versus a program including a single education session, an action plan for self-treatment of exacerbations and monthly follow-up calls from a case manager. Patients in the disease management group experienced a significant reduction in COPD hospitalizations and ED visits combined (41\%). There was also a significant reduction in all-cause hospitalizations and ED visits in the disease management group. More recently, however, a randomized controlled trial (RCT) of patients with COPD hospitalized in the year before study entry and conducted at 20 Veterans Affairs outpatient clinics (27) compared a comprehensive care management program with guideline-based usual care. The program used COPD education, action plans for identification and treatment of exacerbations, and scheduled proactive telephone calls for case management. The trial was stopped early due to unanticipated excess mortality in the intervention group. The conflicting results of these studies reinforced the need to measure the patient care outcomes of our program.

We developed an integrated interdisciplinary program combining strategies previously studied in RCTs (20) and consistent with respiratory guidelines (32), Wagner et al's chronic care model (33) and Naylor et al's transitional care model (23). We focused on patient education, self-management support, following patients across episodes of care and enhanced communication. The nurse-physician partnership and the presence of a nurse navigator to meet the needs of this patient population are pivotal to the success of this program. RCTs are the gold standard to establish the effect of an intervention. After interventions are translated into clinical practice, it is essential to examine whether positive outcomes are generalizable and continue to be observed outside of a trial setting. The results of our quality assurance study highlight the important impact that such a program can achieve in a clinical environment.

It should be noted that, although there are always attempts by the ED to decrease LOS, no hospital-wide specific program was instituted at the JGH during the course of the study. Furthermore, the results indicate decreases in respiratory-cause ED visits and admissions while other-cause visits did not show such changes. Overall practice changes leading to decreases in LOS would also have affected nonrespiratory admissions and are, therefore, unlikely to be the driving force behind the observed changes in respiratory admissions.
The patient population seen by the nurse navigator was heterogeneous. Many patients did not have an ED visit (68\%) or admission (53\%) during their pre period (ie, before their initial visit with the nurse navigator) (Table 1). This observation only strengthens our results because for $>50 \%$ of the study sample, it was not possible to demonstrate a decrease in events but rather there was a potential for increase, especially given the illness trajectory of COPD recently described in a large database with similar patients (8). The analyses compare the number of patients with decreases in events with the number of patients with increases. Significantly more patients experienced a decrease in the number of respiratory-cause ED visits, all-cause and respiratory-cause admissions, as well as reduced total hospital days. Patients with no previous events may have benefitted from the program in other ways; for example, improved functional ability or QoL. Within the scope of the present quality assurance study, the data available do not permit such assessments or the determination of whether certain patients could benefit more than others. More studies are needed to further explore the impact of such programs.

There were some limitations to our study. We had no information regarding care obtained elsewhere and, therefore, could not account for ED visits or admissions outside of our hospital. This, however, is true for both the pre- and postobservation periods. Calculation of the observation period may have been limited by a lack of notification of death for some patients who died outside the hospital. If a patient died before November 5, 2011, this would lead to an overestimation of the length of the preobservation period.

Nearly one-third of patients were referred to the nurse navigator during the time of an ED visit or hospital admission. This index visit was, by the nature of the pre-post design, considered to be part of the preintervention period, possibly biasing the results through regression to the mean. Statistical analyses were performed after removing index visits from the preobservation period. The results from these conservative analyses continued to show that a significant number of patients had reductions in the number of respiratory admissions and total hospital days for respiratory-cause admissions.

An additional limitation involves the classification of ED visits and admissions. ED discharge diagnoses may be likened to preliminary diagnoses and may have been imprecise. Errors in ED discharge diagnoses would impact the classification of ED visits and may have influenced our results. The discharge diagnoses of hospital admissions were obtained from a hospital database (MEDECHO). Although the use of such databases has been questioned for the purpose of identifying patients with a diagnosis (34), it has been shown that they can be robust for classifying admissions in identified patient groups such as COPD (35). Furthermore, the accuracy of the diagnoses has been shown to be higher in academic centres such as ours (34).

Our cost estimates were post hoc analyses limited by various factors. First, we did not track patient health care utilization outside the study centre because it was not within the scope of the present local quality assurance review. It is possible that patients sought urgent care elsewhere. Second, our study was unable to estimate and account for 
added costs to the system that the nurse navigator may have incurred. Examples may include increased outpatient visits, changes in prescriptions and referral for pulmonary rehabilitation. It should be noted, however, that studies have found that hospitalizations represent $>50 \%$ of COPD care costs (19). As such, related costs not estimated in our study may be of lesser importance, and the results of the present study appear to support and justify the strategies and resources added. In view of the reduced number of ED visits and hospital admissions, our integrated interdisciplinary program resulted in annual cost savings $>\$ 260,000$. This decrease was calculated using Mittman et al's reported costs of AECOPD (20). A more recent Canadian study reports even higher costs for AECOPD (36); therefore, our annual savings estimates may be conservative. Bourbeau et al (24) examined health care utilization through a provincial database and found an overall cost saving of $\$ 3,338$ (2004 Canadian dollars) per patient in one year related to case manager support. Applying Bourbeau et al's per patient savings to our patient population $(n=202)$ we would expect a saving of $\$ 674,276$ per annum.

\section{CONCLUSION}

The present quality assurance study suggests that the implementation of an integrated interdisciplinary program for the care of patients with COPD can improve patient outcomes despite the tendency for COPD to worsen over time.

AUTHOR CONTRIBUTIONS: Esther Dajczman, Dr Pierre Ernst, Judy Bianco, Dr Hartley Stern and Dr Mark Palayew conceived and developed the program. All authors were involved in the study design. Esther Dajczman and Dr Chantal Robitaille acquired the data. Dr Chantal Robitaille analysed the data. Esther Dajczman, Dr Chantal Robitaille, Dr Pierre Ernst, Dr Andrew Hirsch and Dr Mark Palayew interpreted the results. Esther Dajczman and Dr Chantal Robitaille wrote the manuscript. Dr. Pierre Ernst, Dr. Andrew Hirsch, Dr. Norman Wolkove, Dr David Small, Judy Bianco, Dr Hartley Stern and Dr Mark Palayew provided critical revisions to the manuscript for intellectual content. All authors gave final approval of the version to be published. The authors thank Maria Veres for her assistance in obtaining the data.

FUNDING: This study was supported by unrestricted grants from Boehringer Ingelheim and Associated Respiratory Holdings.

\section{REFERENCES}

1. Statistics Canada HSD. Leading causes of death in Canada, 2009. Ottawa: Ministry of Industry; 2012. Report No: Catalogue 84-215-XWE.

2. Lacasse Y, Brooks D, Goldstein R. Trends in the epidemiology of COPD in Canada, 1980 to 1995. Chest 1999;116:306-13.

3. Stahl E, Lindberg A, Jansson SA, et al. Health-related quality of life is related to COPD disease severity. Health Qual Life Outcomes 2005;3:56.

4. Joshi M, Joshi A, Bartter T. Symptom burden in chronic obstructive pulmonary disease and cancer. Curr Opin Pulm Med 2012;18.

5. Garrido P, Diez J, Gutierrez J, et al. Negative impact of chronic obstructive pulmonary disease on the health-related quality of life of patients. Results of the EPIDEPOC study. Health Qual Life Outcomes 2006;4:31.

6. Jones PW, Brusselle G, Dal Negro RW et al. Health-related quality of life in patients by COPD severity within primary care in Europe. Respir Med 2011;105:57-66.

7. de Melo M, Ernst P, Suissa S. Rates and patterns of chronic obstructive pulmonary disease exacerbations. Can Respir J 2004;11:559-64.

8. Suissa S, Dell'Aniello S, Ernst P. Long-term natural history of chronic obstructive pulmonary disease: severe exacerbations and mortality. Thorax 2012;67:957-63.

9. Gershon AS, Guan J, Victor JC, Goldstein R, To T. Quantifying health services use for chronic obstructive pulmonary disease. Am J Respir Crit Care Med 2013;187:596-601.
10. Vestbo J, Edwards LD, Scanlon PD, et al. Changes in forced expiratory volume in 1 second over time in COPD. N Engl J Med 2011;365:1184-92.

11. Donaldson GC, Seemungal TAR, Bhowmik A, Wedzicha JA. Relationship between exacerbation frequency and lung function decline in chronic obstructive pulmonary disease. Thorax 2002;57:847-52.

12. Connors AF, Dawson NV, Thomas C, et al. Outcomes following acute exacerbation of severe chronic obstructive lung disease. The SUPPORT investigators (Study to Understand Prognoses and Preferences for Outcomes and Risks of Treatments). Am J Respir Crit Care Med 1996;154:959-67.

13. Soler-Cataluña JJ, Martìnez-Garcìa MÀ, Román Sánchez P, Salcedo E, Navarro M, Ochando R. Severe acute exacerbations and mortality in patients with chronic obstructive pulmonary disease. Thorax 2005;60:925-31.

14. Hurst JR, Vestbo J, Anzueto A, et al. Susceptibility to exacerbation in chronic obstructive pulmonary disease. N Engl J Med 2010;363:1128-38.

15. Bourbeau J, Ford G, Zackon H, Pinsky N, Lee J, Ruberto G. Impact on patients' health status following early identification of a COPD exacerbation. Eur Respir J 2007;30:907-13.

16. Seemungal TAR, Donaldson GC, Paul EA, Bestall JC, Jeffries DJ, Wedzicha JA. Effect of exacerbation on quality of life in patients with chronic obstructive pulmonary disease. Am J Respir Crit Care Med 1998;157:1418-22.

17. Doll H, Miravitlles M. Health-related QOL in acute exacerbations of chronic bronchitis and chronic obstructive pulmonary disease: A review of the literature. Pharmacoeconomics 2005;23:345-63.

18. Chapman KR, Mannino DM, Soriano JB, et al. Epidemiology and costs of chronic obstructive pulmonary disease. Eur Respir J 2006;27:188-207.

19. Chapman KR, Bourbeau J, Rance L. The burden of COPD in Canada: Results from the confronting COPD survey. Respir Med 2003;97(Suppl C):S23-S31.

20. Mittmann N, Kuramoto L, Seung SJ, Haddon JM, Bradley-Kennedy C, FitzGerald JM. The cost of moderate and severe COPD exacerbations to the Canadian healthcare system. Respir Med 2008;102:413-21.

21. Bourbeau J, Julien M, Maltais F, et al. Reduction of hospital utilization in patients with chronic obstructive pulmonary disease: A disease-specific self-management intervention. Arch Intern Med 2003;163:585-91.

22. Rea H, McAuley S, Stewart A, Lamont C, Roseman P, Didsbury P. A chronic disease management programme can reduce days in hospital for patients with chronic obstructive pulmonary disease. Intern Med J 2004;34:608-14.

23. Naylor MD. Transitional care: A critical dimension of the home healthcare quality agenda. J Healthc Qual 2006;28:48-54.

24. Bourbeau J, Collet JP, Schwartzman K, Ducruet T, Nault D, Bradley C. Economic benefits of self-management education in COPD. Chest 2006;130:1704-11.

25. Naylor MD, Brooten D, Campbell R, et al. Comprehensive discharge planning and home follow-up of hospitalized elders. JAMA 1999;281:613-20.

26. Bank of Canada. Bank of Canada Price Index, 2012. $<$ www.bankofcanada.ca/rates/price-indexes/cpi/> (Accessed Ocotber 15, 2012).

27. Fan VS, Gaziano JM, Lew R, et al. A comprehensive care management program to prevent chronic obstructive pulmonary disease hospitalizations: A randomized, controlled trial. Ann Intern Med 2012;156:673-83.

28. Rice KL, Dewan N, Bloomfield HE, et al. Disease management program for chronic obstructive pulmonary disease. Am J Respir Crit Care Med 2010;182:890-6.

29. Hermiz O, Comino E, Marks G, Daffurin K, Wilson S, Harris M. Randomised controlled trial of home based care of patients with chronic obstructive pulmonary disease. BMJ 2002;325:938.

30. Gallefoss F, Bakke PS. Impact of patient education and selfmanagement on morbidity in asthmatics and patients with chronic obstructive pulmonary disease. Respir Med 2000;94:279-87.

31. Gallefoss F, Bakke PS, Kjaersgaard P. Quality of life assessment after patient education in a randomized controlled study on asthma and chronic obstructive pulmonary disease. Am J Respir Crit Care Med 1999;159:812-7. 


\section{Dajczman et al}

32. O'Donnell DE, Aaron S, Bourbeau J, et al. Canadian Thoracic Society recommendations for management of chronic obstructive pulmonary disease - 2007 update. Can Respir J 2007;14(Suppl B):5B-32B.

33. Wagner EH. Chronic disease management: What will it take to improve care for chronic illness. Eff Clin Pract 1998;1:2-4.

34. Lacasse Y, Daigle J-M, Martin S, Maltais F. Validity of chronic obstructive pulmonary disease diagnoses in a large administrative database. Can Respir J 2012;19:e5-e9.
35. McKnight J, Scott A, Menzies D, Bourbeau J, Blais L, Lemière C. A cohort study showed that health insurance databases were accurate to distinguish chronic obstructive pulmonary disease from asthma and classify disease severity. J Clin Epidemiol 2005;58:206-8.

36. Maleki-Yazdi MR, Kelly SM, Lam SS, Marin M, Barbeau M, Walker V. The burden of illness in patients with moderate to severe chronic obstructive pulmonary disease in Canada. Can Respir J 2012;19:319-24. 


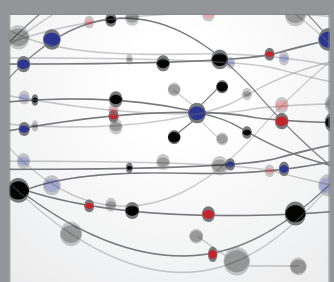

The Scientific World Journal
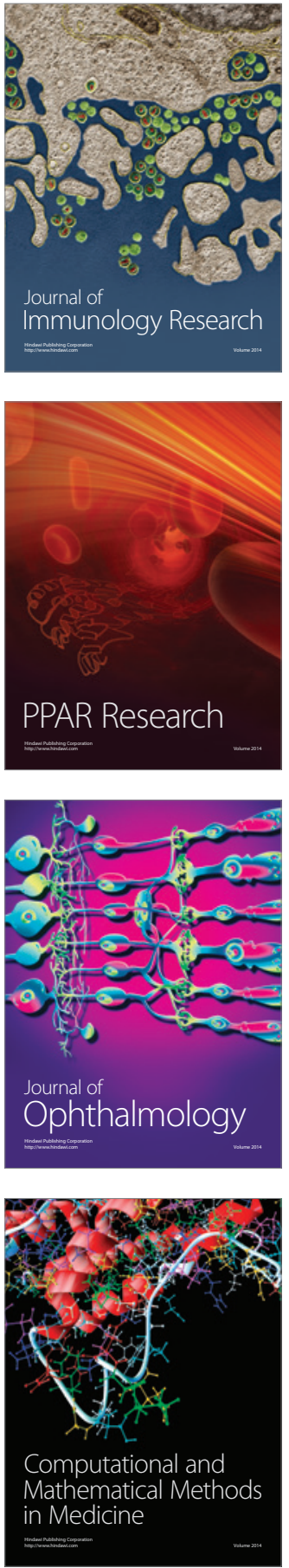

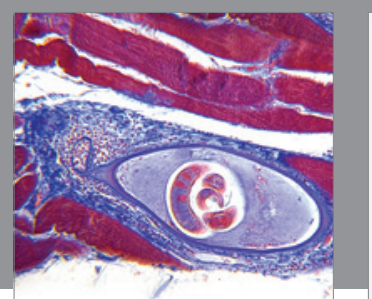

Gastroenterology Research and Practice

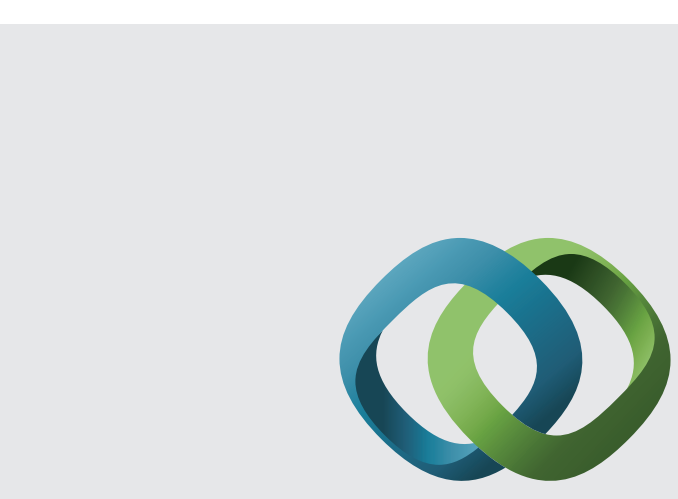

\section{Hindawi}

Submit your manuscripts at

http://www.hindawi.com
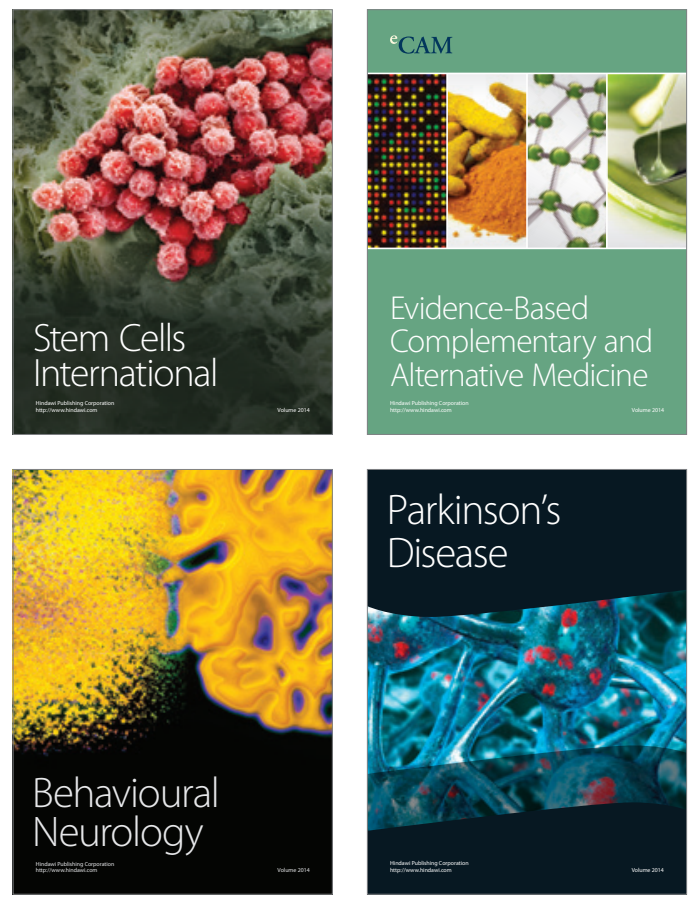
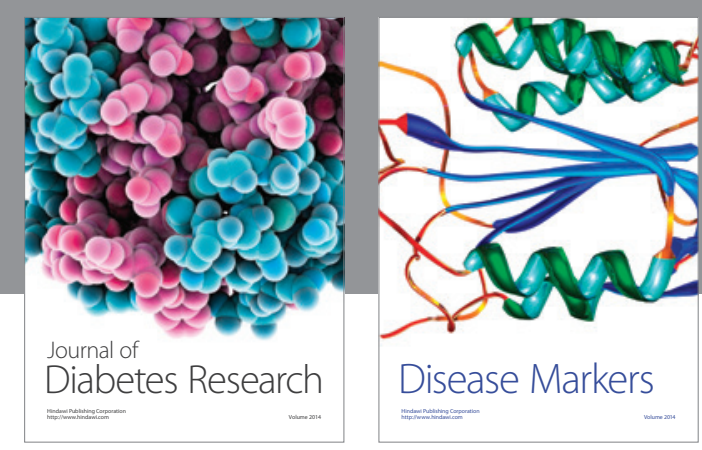

Disease Markers
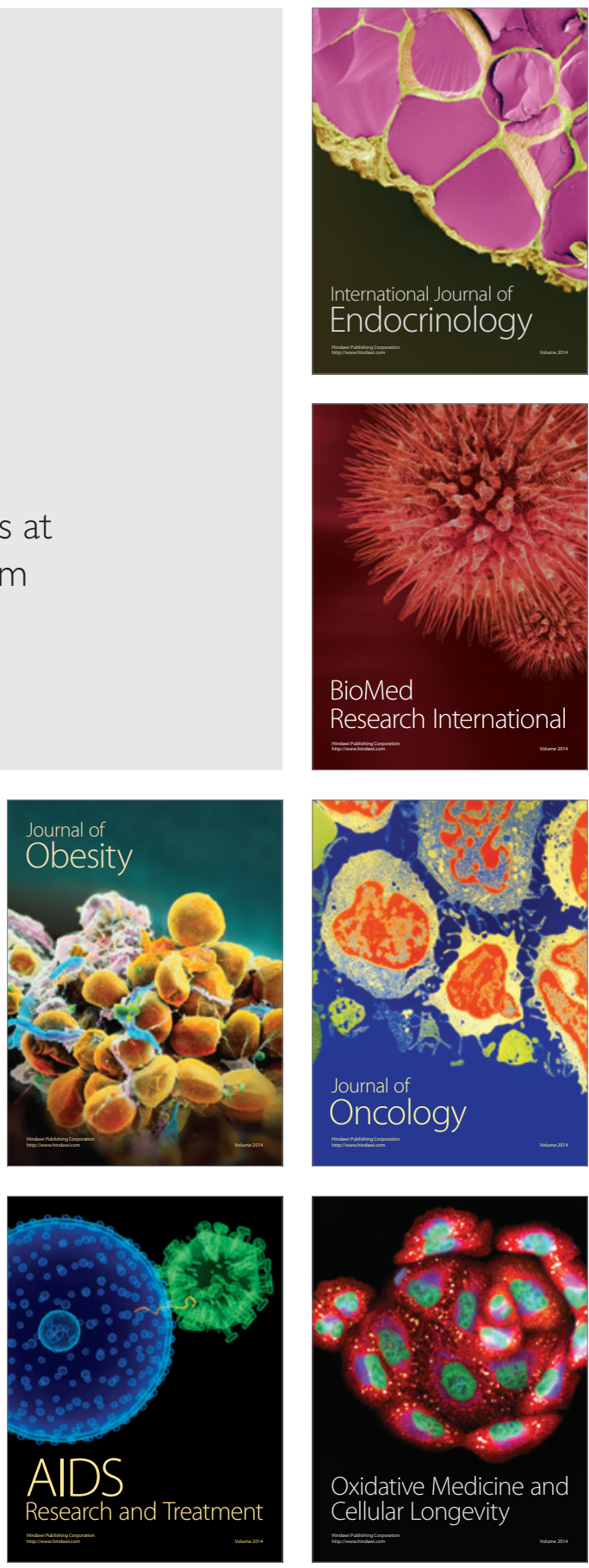